\title{
Study on the fatigue and wear characteristics of four wheel materials
}

\author{
G. Y. Zhou • J. H. Liu $\cdot$ W. J. Wang • \\ G. Wen $\cdot$ Q. Y. Liu
}

Received: 15 May 2013/Revised: 18 August 2013/Accepted: 20 August 2013/Published online: 10 September 2013

(C) The Author(s) 2013. This article is published with open access at Springerlink.com

\begin{abstract}
The fatigue and wear characteristics of four different steel wheel materials are investigated in detail by using rolling contact fatigue and wear bench tests on a JD-1 apparatus, analyzing chemical composition and hardness, and performing profile analysis and micro-morphology analysis. The wear and fatigue behavior of one of the materials under different operation speeds is also investigated. The results show that the wear resistance of the materials has a positive correlation with their carbon content, while fatigue resistance has a negative correlation. Based on hardness analysis as a function of depth into the specimen, the thickness of layers with a steep hardness gradient has a negative correlation with the initial surface hardness in the tests using different materials. The hardness increments, however, have a positive correlation with initial surface hardness. The rolling tests on one material using different rotation speeds show that the hardness increments and the thickness of layers with a steep hardness gradient increase with the rotation speed. The analyses and experimental results demonstrate that two of the four materials exhibit good wear resistance and rolling contact fatigue resistance, making them suitable for either highspeed or heavy axle railroad operations.
\end{abstract}

Keywords Wheel material · Fatigue $\cdot$ Wear $\cdot$ Hardness

G. Y. Zhou ( $\bowtie) \cdot$ J. H. Liu · W. J. Wang · G. Wen · Q. Y. Liu State Key Laboratory of Traction Power, Tribology Research Institute, Southwest Jiaotong University, Chengdu 610031, China

e-mail: zhouguiyuangift@sina.cn

\section{Introduction}

Researching high-performance wheel materials is important in wheel/rail development in order to reduce the wear between wheel and rail and prolong service life [1]. In the USA, Robles Hernández et al. [2] developed a high performance wheel steel, called SRI wheel steel, and compared it with seven other high-performance wheels, six pearlitic and one bainitic, manufactured by different companies. In China, Mi et al. [3] researched the wear characteristics of two types of cast steel wheel materials, which were named $\mathrm{B}+$ and $\mathrm{B}$ grades of steel. Experimental inquiry is very important in new wheel material research, such as the experiments done by Cvetkovski et al. [4] using low-cycle fatigue tests on a new wheel material for passenger trains.

Wear is the most critical factor in the replacement of rails and wheels in commercial railroad systems, and in restricting the service life of wheels. Enhancing the wear resistance of wheels, therefore, can bring economic benefit to railway operations, and a large amount of railway research is spent on reducing the wear between the wheel and rail by simply reducing the weight loss or by reducing special wear forms such as corrugation.

We know that the hardness of a material directly relates to wear, and that increasing the hardness of the steel can reduce the wear of wheels and rails. There is a limit to the benefit of increasing the hardness of the wheel and rail, however, and simply improving the hardness of material to reduce the wear is not an effective method. Many studies have shown that a plastic deformation layer on the surface of hard steel is formed during wearing, significantly increasing the hardness of the worn surface [5-8]. This forms a special material which consists of a hard external material and a tough internal material which is ideal for 
railway operation. However, depending upon plastic deformation to improve surface hardness is a limited technique.

The roughness of surfaces can increase considerably during rolling contact experiments, which can cause high contact pressure and lead to plastic deformation of the materials [9]. The plastic deformation can accumulate, called ratcheting, and can ultimately lead to failure due to cracking. However, the contact surface asperities between the wheel and rail contribute to the tangential friction force at the wheel/rail interface, resulting in an increase of the adhesion coefficient [10]. Therefore, if the interface roughness can be held at a suitable value, it would be beneficial for operation safety and maintenance.

Fatigue of a material results in conditions such as fracture toughness and fracture brittleness, but the level of fatigue of a material is always evaluated by cracks and service time. In the railway industry, fatigue cracks are produced by abnormal braking heat [11], and the service time of a material is defined as the period from initial use to the time of fatigue crack initiation [12]. Finite element analysis (FEA) can simulate fatigue crack initiation effectively and conveniently, but experimental methods can directly obtain fatigue characteristics and are more reliable.

In this paper, the wear and fatigue characteristics of four different wheel materials are investigated using the JD-1 wheel/rail simulation facility and special analysis methods. Material weight loss is measured by weighing, and measurements of the surface, hardness, and fatigue cracks are performed using a scanning electron microscope (SEM) and an optical microscope.

\section{Experimental details}

\subsection{Materials}

The four types of wheel steel in this study are intended for trains, and the number labeling and chemical compositions in weight percentage of these materials are shown in Table 1. The carbon content of materials \#3 and \#4 were slightly higher than common wheel materials $[4,7,13]$. The main difference in composition among the four materials was the amount of carbon, which varied from $0.51 \%$ to $0.72 \%$. The steel of the rail roller used was U71Mn rail steel, which is discussed in [14].

The pearlite microstructure of the four materials is shown in Fig. 1, revealing the typical ferritic-pearlitic structure which is tough and ductile, but soft. As the carbon content was increased, the amount of pro-eutectoid ferrite decreased and the micro-hardness increased, as listed in Table 2. Although there was no specific measurement of the pearlitic grain size, the grain size of the \#1 material was clearly the smallest, and the pearlitic grain sizes increase with the carbon content.

The surface hardness of the materials as listed in Table 2 was measured on a micro-hardness tester (MVK-H21, Japan) using a $200 \mathrm{~g}$ load. Each specimen was measured at five different points to reduce the errors due to material non-uniformity, and each point was measured five times.

The surface hardness of the materials relates to the carbon content and metallographic analysis, as discussed previously, with our \#1 material exhibiting the smallest value of hardness and \#4 exhibiting the greatest.

\subsection{Methods}

Prior to the rolling tests, the mass, roughness, and hardness of the specimens were measured. The rolling contact fatigue test was then carried out, and the weight, roughness, and hardness of the specimens were subsequently measured again. To analyze the wear and fatigue damage mechanisms in the wheel materials, SEM was used to observe subsurface cracks and the scar morphology, and an optical microscope was used to analyze plastic deformations near the surface.

All experiments were carried out on a JD-1 wheel/rail simulation facility apparatus [7], as shown in Fig. 2. The tester was composed of a small wheel which served as the locomotive or rolling stock (called the "wheel roller") and a large wheel which served as the rail (called the "rail roller"). The rail roller was driven by a DC motor, and an opposing torque unit generated an opposing torque against the rotation direction imposed on the wheel roller.

The geometric size of the rollers was determined using the Hertzian simulation rule, shown in Eqs. (1) and (2):

Table 1 Compositions of four wheel materials in mass fraction (\%)

\begin{tabular}{llllllllllll}
\hline Number & $\mathrm{C}$ & $\mathrm{Mn}$ & $\mathrm{Si}$ & $\mathrm{P}$ & $\mathrm{S}$ & $\mathrm{H}$ & $\mathrm{Cr}$ & $\mathrm{Ni}$ & $\mathrm{Mo}$ & $\mathrm{V}$ \\
\hline$\# 1$ & 0.51 & 0.75 & 0.28 & 0.016 & 0.002 & 1.4 & 0.22 & 0.01 & 0.01 & 0.01 & 0.02 \\
$\# 2$ & 0.58 & 0.72 & 0.25 & 0.012 & 0.001 & 0.8 & 0.18 & 0.01 & 0.01 & 0.01 & 0.01 \\
$\# 3$ & 0.62 & 0.79 & 0.82 & 0.013 & 0.012 & 1.2 & 0.17 & 0.01 & 0.01 & 0.01 & 0.03 \\
$\# 4$ & 0.72 & 0.81 & 0.86 & 0.014 & 0.016 & 2 & 0.02 & 0.01 & 0.01 & 0.01 & 0.02 \\
\hline
\end{tabular}



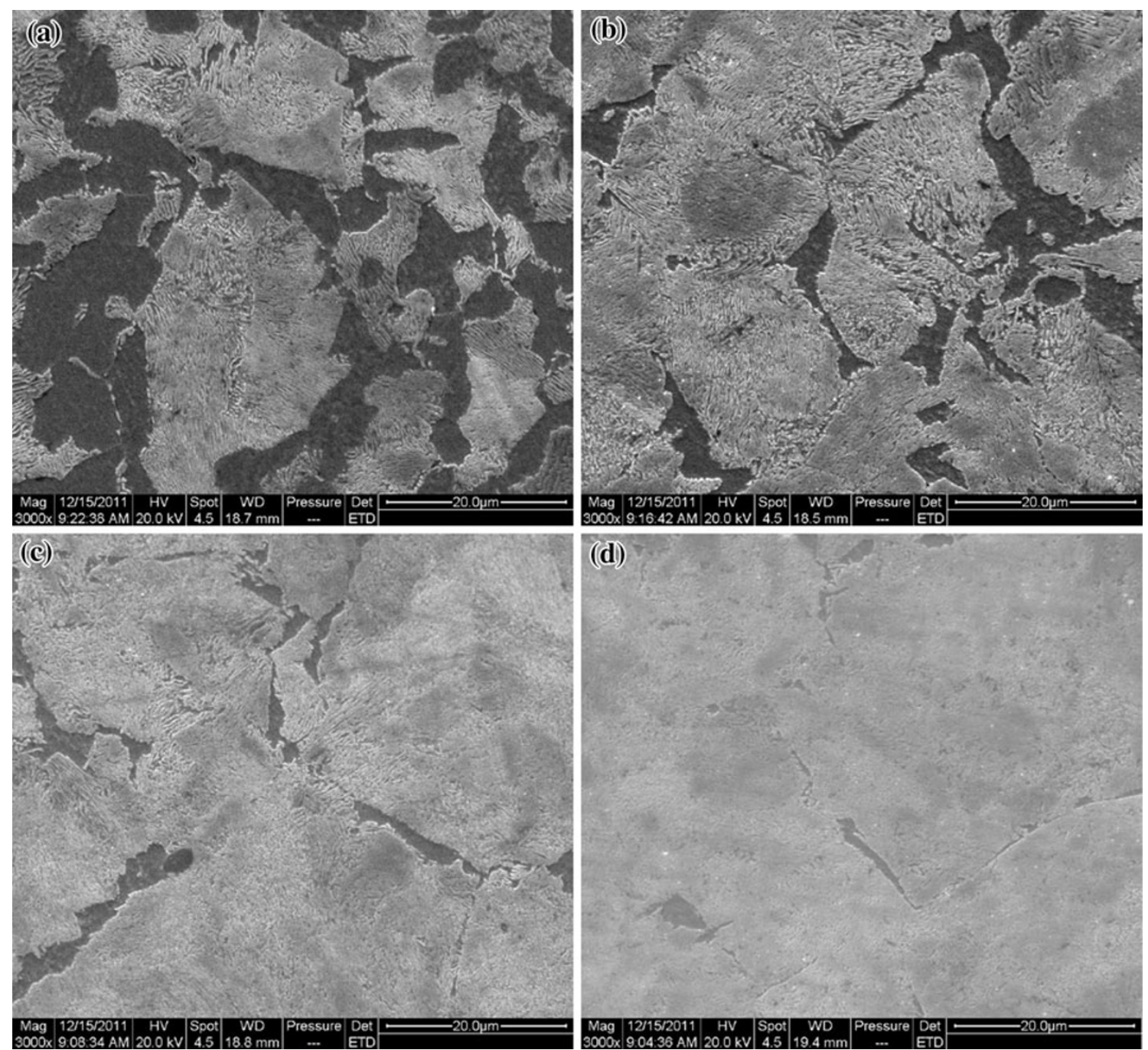

Fig. 1 SEM graphs of the pearlite microstructure $(3,000 \times)$. a \#1 material. b \#2 material. c \#3 material. d \#4 material

Table 2 The surface hardness of materials

\begin{tabular}{lllll}
\hline Number of material & $\# 1$ & $\# 2$ & $\# 3$ & $\# 4$ \\
\hline Hardness $\left(\mathrm{HV}_{200 \mathrm{~g}}\right)$ & 252.95 & 274.28 & 303.47 & 330.82 \\
\hline
\end{tabular}

$\left(P_{\max }\right)_{\text {field }}=\left(P_{\max }\right)_{\mathrm{lab}}$,

$\left(\frac{a}{b}\right)_{\text {field }}=\left(\frac{a}{b}\right)_{\text {lab }}$,

where $\left(P_{\text {max }}\right)_{\text {lab }}$ and $\left(P_{\text {max }}\right)_{\text {field }}$ are the maximum contact stresses in the laboratory and in the field, respectively; and $(a / b)_{\text {lab }}$ and $(a / b)_{\text {field }}$ are the ratios of the semi-major axis to the semi-minor axis of the contact ellipses between the wheel and rail in the laboratory and field, respectively. The schema of the rollers' geometric sizes as calculated by the above equations is shown in Fig. 3.

All experiments were conducted in dry and ambient conditions (temperature $18-23{ }^{\circ} \mathrm{C}$, relative humidity
$50 \%-70 \%$ ), and all contact surfaces were cleaned with acetone prior to testing. All experimental parameters were determined by means of the Hertzian simulation [1], with the diameter of the rail roller set at $1,050 \mathrm{~mm}$ and the diameter of the wheel roller, which was cut from an actual wheel, set at $68 \mathrm{~mm}$. The total number of cycles undergone by the wheel roller was $10^{6}$, and the normal load used in the laboratory was $1,420 \mathrm{~N}$, which simulated an actual field axle load of $19 \mathrm{t}$. The corresponding maximum contact stress as calculated by the Hertz formulae was 1,242 $\mathrm{MPa}$. The rotation speeds of the wheel rollers were 32, 69, and $94 \mathrm{r} / \mathrm{min}$, which simulated train speeds of 120,250 , and $350 \mathrm{~km} / \mathrm{h}$, respectively. Using an attack angle, which is the angle between the axes of the wheel and rail rollers, to simulate the curvature of an actual track, we used an attack angle of $0.3772^{\circ}$ to simulate a curvature radius of $2,000 \mathrm{~m}$. To simulate the traction condition, a force of $100 \mathrm{~N}$ was applied on the opposing torque unit to generate an 


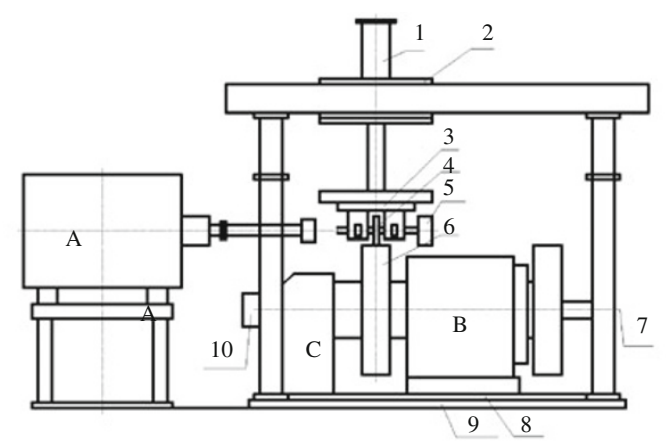

(a)

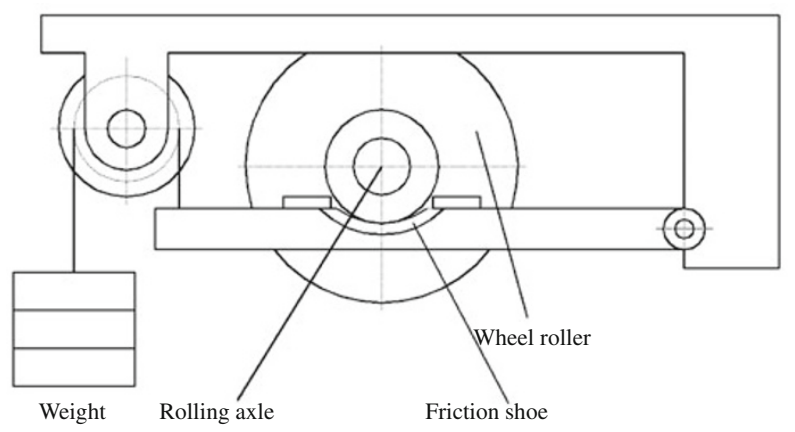

(b)

Fig. 2 Scheme of JD-1 wheel/rail simulation facility. a JD-1 wheel/ rail simulation facility. 1 Normal loading cylinder, 2 loading carriage, 3 3D loading sensor, 4 wheel roller, 5 opposing torque unit, 6 rail roller, 7 speed measuring motor, 8 turning plate, 9 base plate, 10 optical shaft encoder. b Opposing torque unit

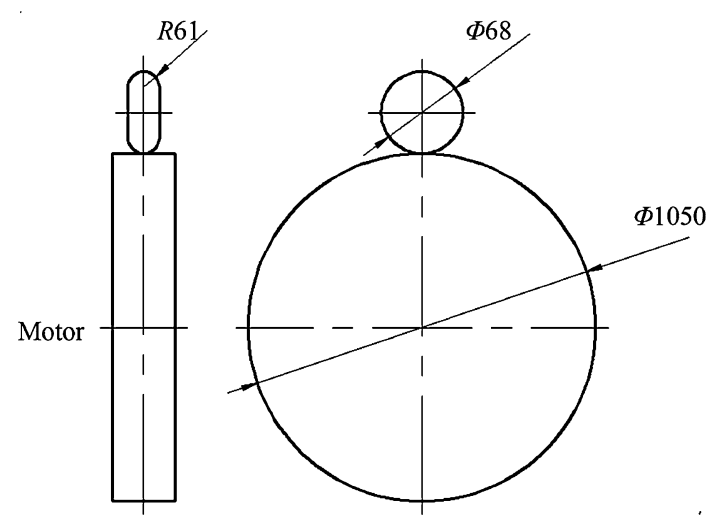

Fig. 3 Scheme of the wheel and rail rollers

opposing torque (Fig. 2b). The main parameters of all experiments are listed in Table 3.

\section{Experimental results}

A photograph of the four specimens after the rolling test for different materials (specimens A-D), together with a ruler, is shown in Fig. 4a. It is obvious that the width of the wear scars on the wheels decreases with the specimen series, from specimen A-D. Since all specimens have approximately the same original profile, it is logical to conclude that the wear resistance has a positive correlation with the carbon content of the material.

In addition, there exists an uneven wear phenomenon on all of the specimens, especially in specimens B, C, E, and F. Specimen E, obtained with rolling tests using different speeds, exhibits another unusual wear phenomenon of smooth areas, as pointed out in Fig. 4b. Also obtained in tests using different speeds, the corrugation pattern of specimen $\mathrm{F}$ is well-distributed along the circumferential direction, exhibiting smooth (trough) and unsmooth (crest) areas with a distance between of about $1 \mathrm{~mm}$.

\subsection{Scars of specimens under SEM}

After rolling contact tests, small slices are cut from the specimens and cleaned using ultrasonic cleaning with alcohol and acetone before being observed with SEM (QUANTA200, FEI, England). The morphology of the scars evident on the specimen surfaces are shown in Fig. 5.

Analysis of the rolling surfaces shows the occurrence of flaking and adhesive wear for all specimens, including specimens $\mathrm{E}$ and $\mathrm{F}$ in Fig. 6. Surface ratcheting cracks are most evident in specimen $\mathrm{D}$, and an example of one is shown in Fig. 5(d). Ratcheting cracks occur when the material loses its ductility due to plastic strain accumulation [15]. Specimens A, B, and C shows evidence of adhesive wear rather than flaking. This may indicate that the occurrence of the ratcheting phenomena in specimens $\mathrm{A}, \mathrm{B}$, and $\mathrm{C}$ is not as great as in specimen $\mathrm{D}$, which may be due to the differences in carbon content and metallographic structure.

The worn surfaces of specimens $\mathrm{E}$ and $\mathrm{F}$, tested using rotation speeds of 32 and $94 \mathrm{rpm}$, respectively, exhibit uneven wear phenomena (Fig. 6). Both the morphology of the scars and the wear mechanisms are different at different regions of uneven wear, as can be seen in Fig. 6b, c, e, and f. At the crest the surface is much rougher and ratcheting is the dominant wear mechanism, while in the trough the surface is smoother and adhesive wear is as significant as ratcheting effects. The special wear phenomenon called smooth area wear is observed macroscopically in Fig. 4b, and is observed at high magnification using SEM in Fig. 6a.

\subsection{Weight loss and profile analysis}

Figure 7 shows the material weight loss against the carbon content of all specimens during all tests. The weight loss is obtained using an electronic scale (JA4103, China) before 
Table 3 Test parameters

\begin{tabular}{llll}
\hline Test type & $\begin{array}{l}\text { Specimen } \\
\text { series }\end{array}$ & $\begin{array}{l}\text { Rotational speed } \\
\text { of simulating } \\
\text { rail (rad/min) }\end{array}$ & $\begin{array}{l}\text { Material } \\
\text { number }\end{array}$ \\
\hline $\begin{array}{l}\text { Test for different } \\
\text { materials }\end{array}$ & A & 69 & $\# 1$ \\
& B & 69 & $\# 2$ \\
Test under different & C & 69 & $\# 3$ \\
speed & E & 69 & $\# 4$ \\
\hline
\end{tabular}

and after the rolling tests, and is a direct way to obtain the weight loss of specimens. The results indicate that the wear resistance is directly related to the carbon content, and specimens with a higher carbon content have greater wear resistance. Particularly, the least weight loss occurs in specimen D, which has the highest carbon content, and the greatest weight loss occurs in specimen a, which has the lowest carbon content. Specimens C, E, and F use the same material (\#3) with different rotation speeds, and the weight loss is seen to have a negative correlation with the experimental rotation speed.

\subsection{Results of test for different materials}

The variation of surface hardness as a function of depth is measured to study the work-hardening effect, and the results are presented in Fig. 8. These plots show that the hardness of the specimens changes rapidly nearest the rolling surface (i.e., steep hardness gradient), and changes at a less rapid rate after a certain depth into the surface (i.e., gradual hardness gradient). The thickness of the hardened layer of all specimens is more than $200 \mu \mathrm{m}$. Comparing the post-experiment hardness values (Fig. 8) with the initial surface hardness of different materials (Table 2), we can see that the hardened layers are thicker than the plastic deformation layers observed in Figs. 9 and 10.
In the rolling tests of different materials (Fig. 8a), for the layers displaying a steep hardness gradient, the thickness of these layers has a negative correlation with the initial surface hardness, while the hardness increments have a positive one. This result is consistent with the results of the thickness of plastic deformation in Fig. 9.

For comparison, rolling tests with different rotation speeds using the \#3 material show both the hardness increments and the thickness of layers displaying a steep hardness gradient of the three specimens to increase with rotation speed (Fig. 8b). These results are consistent with the results in Fig. 10. It is obvious that the dominant wear damage mechanism in the specimen with high surface hardness and with high experimental rotation speed is ratcheting rather than an adhesive wear mechanism. It is known that ratcheting can lead to fatigue cracks at the nearsurface layer, so generating fatigue failure will therefore be easier in the cases involving high surface hardness and high experimental rotation speed.

Both the plastic deformation and the hardness increments have a positive correlation with the contact stress. Some research indicates that severe plastic deformations in the near-surface layer of the rail cross-section penetrate just a few tens of microns into the material $[9,11,15]$. In Fig. 8 we see that at thicknesses greater than about $100 \mu \mathrm{m}$ into the material, the hardness gradient is quite gradual.

The results of the SEM observations are shown in Fig. 11, and the observation schematic is shown in Fig. 12. It is obvious that the fatigue resistance of specimen $A$ is so perfect that no cracks can occur, and that the length of fatigue cracks in the other specimens increase as a function of increasing carbon content. In other words, the fatigue resistance decreases with carbon content in this rolling test. Moreover, all of the fatigue cracks propagate from the surface into the material at approximately the same angle.

Examining the cross sections of specimens from A to D with an optical microscope (OLYMPUS BX60M, Japan), we can observe significant plastic bands due to ratcheting,
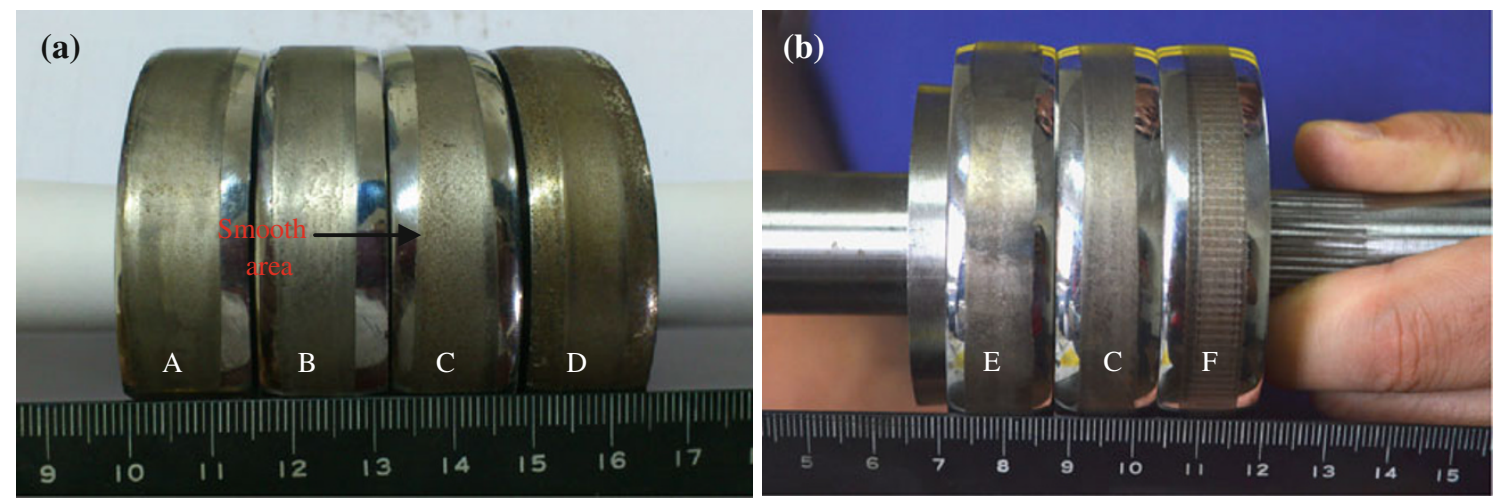

Fig. 4 Macrograph of specimens. a For different materials. b For different speeds 

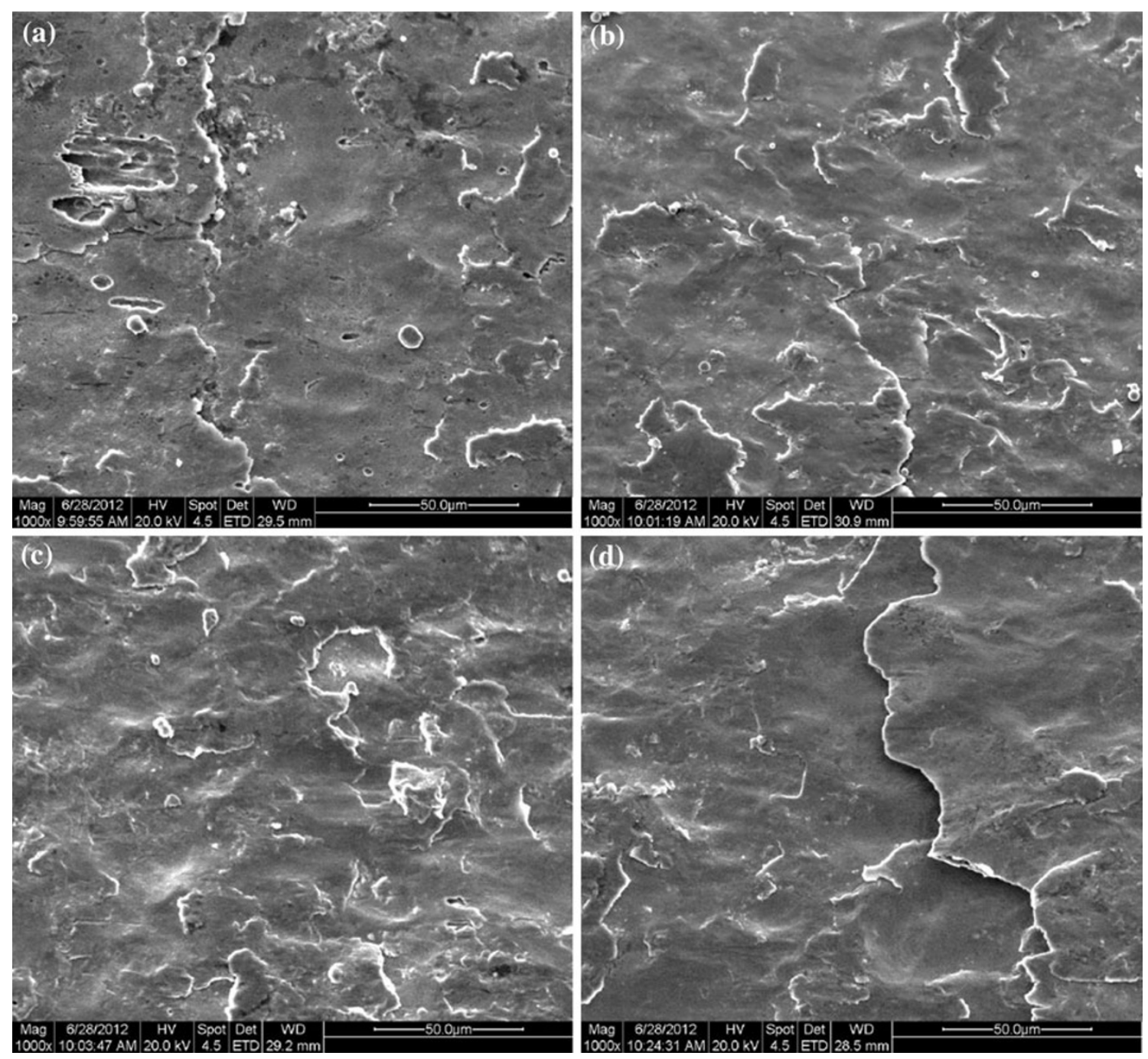

Fig. 5 Scars of specimens A to D under SEM. a Specimen A. b Specimen B. c Specimen C. d Specimen D

as shown in Fig. 9. The plastic deformation of specimens A and $\mathrm{B}$ are mild, while the deformations of specimens $\mathrm{C}$ and $\mathrm{D}$ are severe. In addition, both specimens $\mathrm{C}$ and $\mathrm{D}$ exhibit significant fatigue cracks.

\subsection{Results of test for different rotational speeds}

Optical microscope images of the cross sections of specimens $\mathrm{E}$ and F, un-etched after polishing, are shown in Fig. 13. These images show that longer fatigue cracks occur after the higher rotation speed is applied (Fig. 13b), but the amount of small cracks is greater at the lower rotation speed (Fig. 13a).

The thickness of the deformed layer is measured to be about $115 \mu \mathrm{m}$ for specimen $\mathrm{E}$ and about $180 \mu \mathrm{m}$ for specimen $F$ (Fig. 10). The deformed layer of specimen $F$ is much thicker than that of $\mathrm{E}$, and is related to wear rate and ratcheting. The wear rate is greater at lower rotation speeds, but the effect of ratcheting is almost the same for all speeds in the test, so the deformed layer increases more slowly at a slower rotation speed.

\section{Discussion}

The wear process of materials is very complex. During the initial stages of the rolling-sliding process, the strain accumulation and hardening rate is strongest and oxidative wear is the main wear mechanism [16]. The initial hardening of the material plays an important role during the whole wear process of wheel and rail. If there is a hardening layer on the surface of the rollers and if the load is insufficient to generate severe flaking during the subsequent operation, the material, which has internal toughness and an induced external hardness, can experience reduced wear and fatigue damage and convey an extended service life for rollers composed of it. 

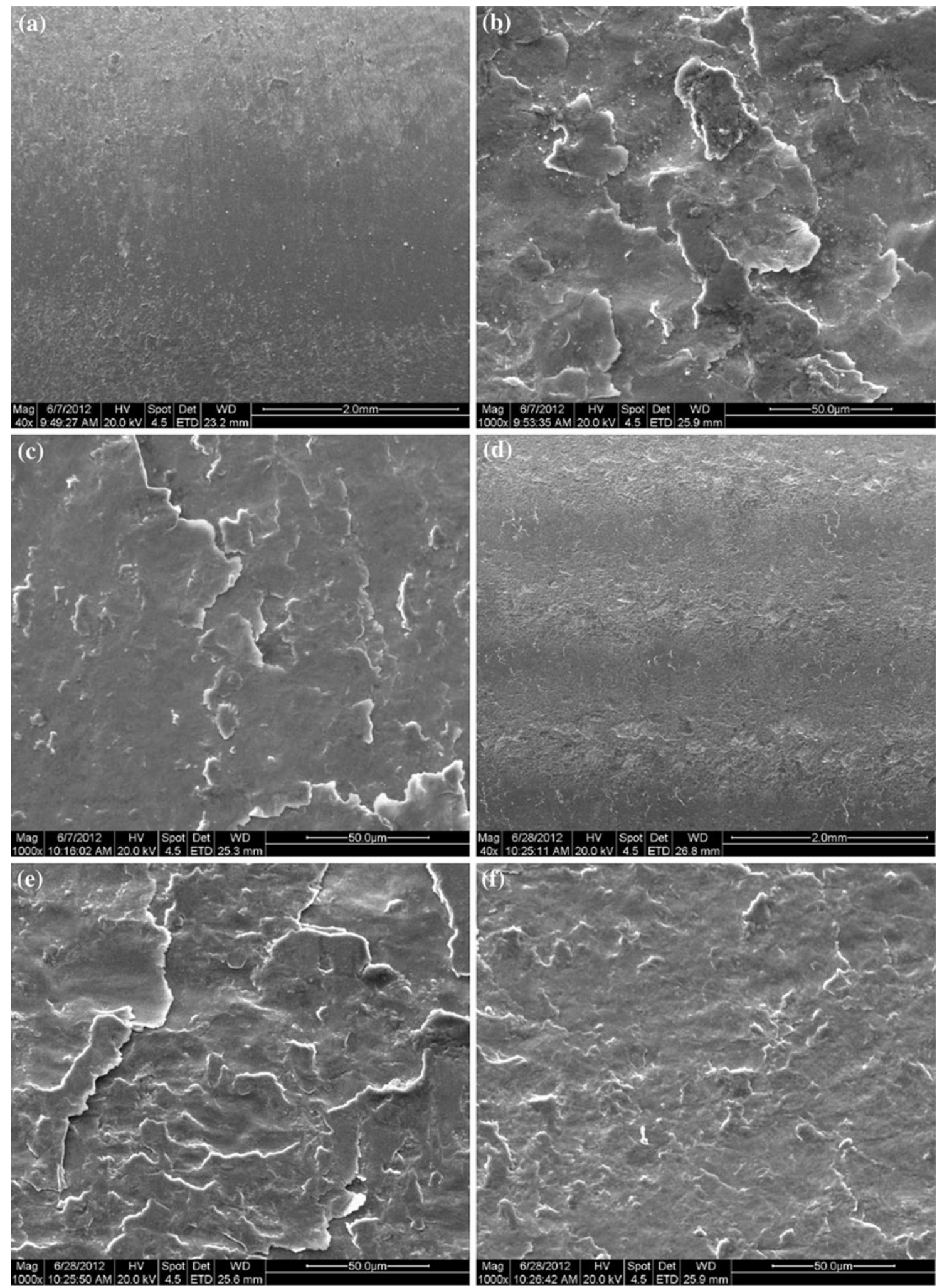

Fig. 6 Scars of specimens E and F under SEM. a Smooth area of specimen E. b Crest of specimen E. c Trough of specimen E. d Uneven wear pattern of specimen F. e Crest of specimen F. f Trough of specimen F 

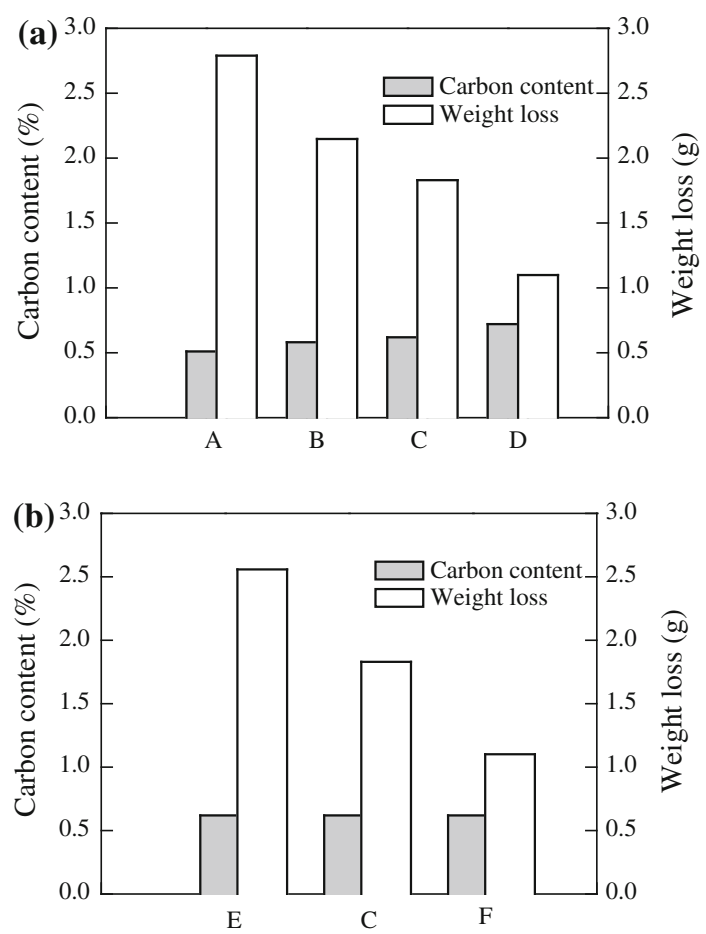

Fig. 7 The weight loss of six specimens. a For different materials. b For different rotational speeds

To some extent, strain accumulation (ratcheting) and wear are competitive mechanisms, with one reducing the influence the other has on the material. Ratcheting can cause subsurface hardening which can slow down the wear rate directly (higher hardness means greater wear resistance), and therefore ratcheting can reduce wear. Conversely, wear reduces the influence of ratcheting via material attrition. No matter which, if one process becomes dominant, then severe damage, such as severe wear and/or fatigue fractures, is the result. Therefore, the best relationship to maintain between rail and wheel is a balance of ratcheting and wear in order to achieve the state of steady wear [16], thereby facilitating maximum service life.

There also exists a competitive and restrictive coupling mechanism between wear and plastic deformation, which is described by Zhong [14]. The plastic deformation and fatigue cracks formed by the ratcheting effect [17] can improve the wear resistance of the material, but the increase in hardness of the surface and subsurface can reduce the fatigue resistance.

Analysis of the rolling surface of these materials shows the occurrence of flaking due to ratcheting and the adhesive wear mechanism for all specimens, but uneven wear gives evidence that the wear mechanism varies in different regions of the surface. The relationship between flaking due to ratcheting and the adhesive wear mechanism could impact the morphology of these scars.
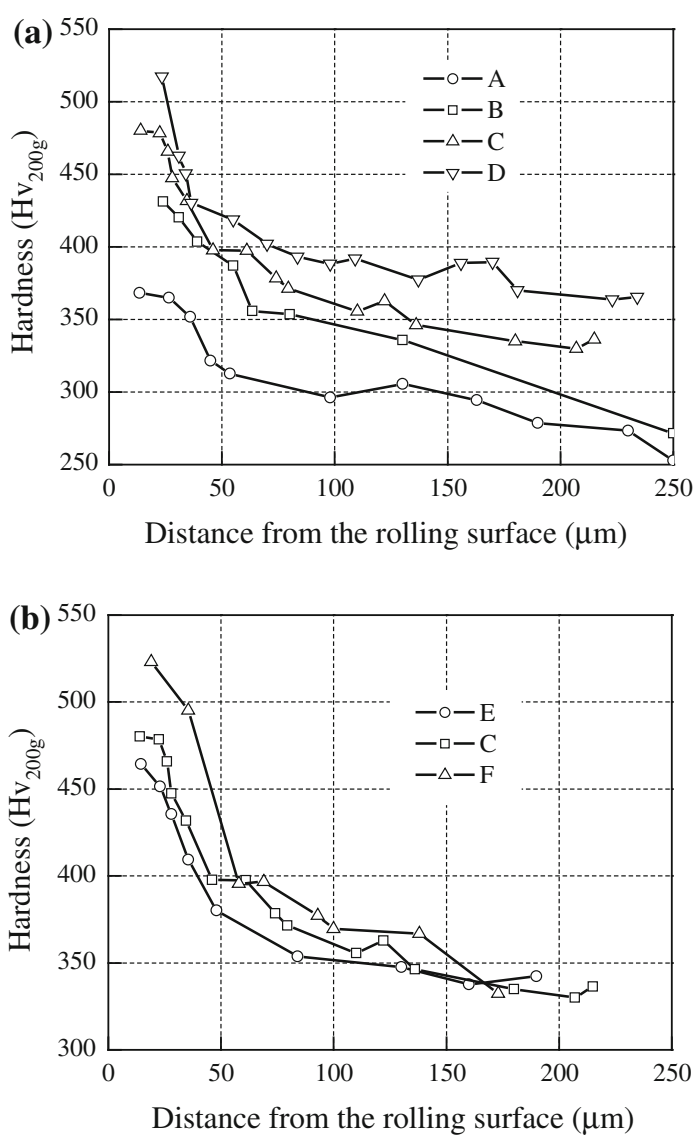

Fig. 8 The variation of hardness as a function of depth from the rolling-sliding surface

The differing carbon content of the wheels leads to the different damage forms of their surfaces. As the carbon content increases, there is a gradual transition from a weardominant to a fatigue-dominant mechanism due to the competitive and restrictive coupling between wear and fatigue, with the stronger mechanism becoming dominant.

The material presents a wear-dominant mechanism when the carbon content is lower and a fatigue-dominant mechanism when the carbon content is higher. The wear mechanism is more apparent than other damage forms in specimens $\mathrm{A}$ and $\mathrm{B}$, with specimen $\mathrm{A}$ showing more wear mechanism than specimen B. With an increase in the carbon content, the length of fatigue cracks increase, showing more evidence of the fatigue damage mechanism on the surface of specimens. Consequently, specimens $\mathrm{C}$ and $\mathrm{D}$ present a more dominant fatigue damage mechanism than specimens $\mathrm{A}$ and $\mathrm{B}$.

In Fig. 7, the weight loss of specimens $\mathrm{A}$ and $\mathrm{B}$ is greater than specimens $\mathrm{C}$ and $\mathrm{D}$, which means there is more wear damage on specimens A and B. When we look at the evidence given by the combined Figs. 9 and 11, we see that when wear is the dominant damage form (A, B), the plastic deformation is slighter and almost no fatigue cracks exist on the surface layer. 

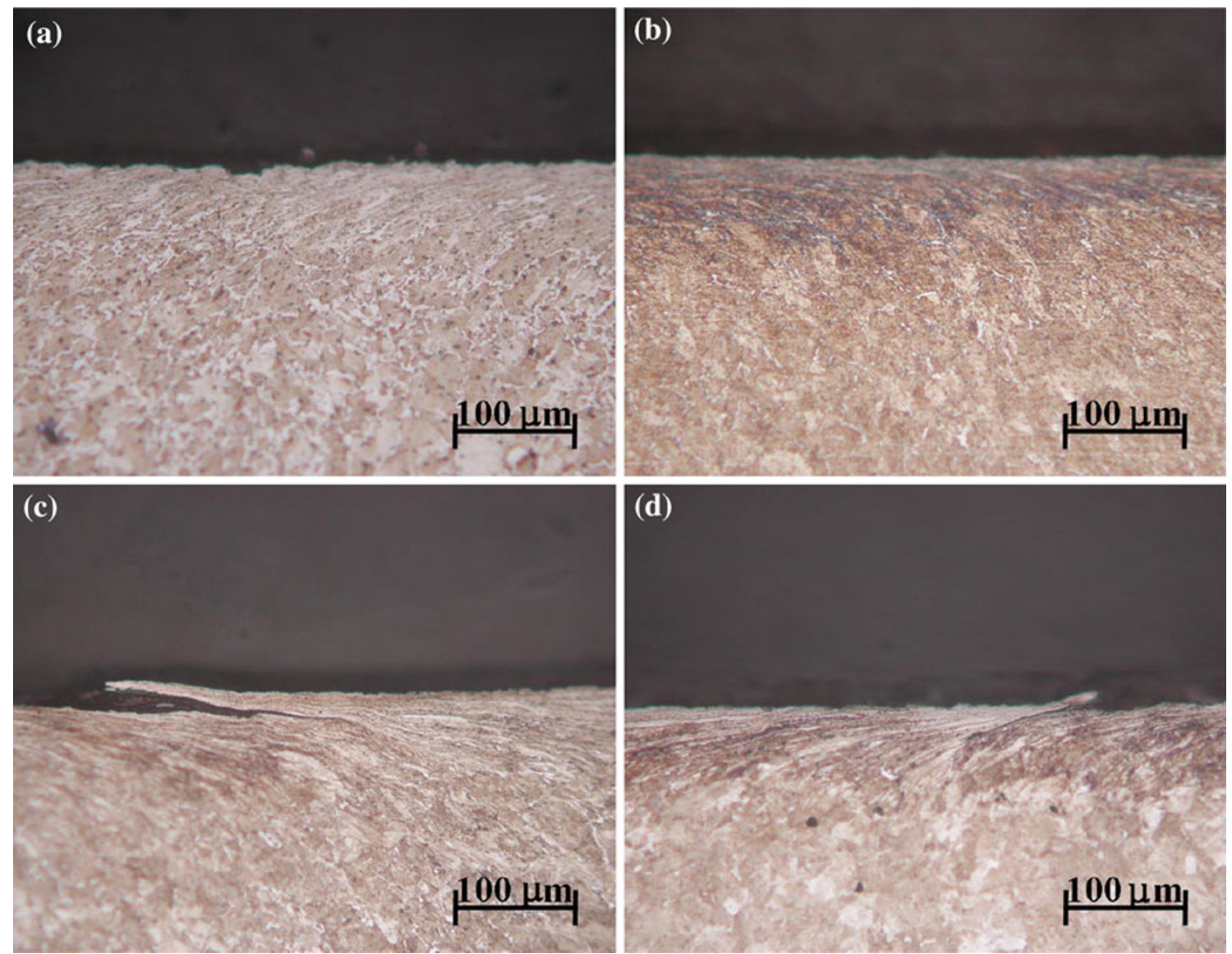

Fig. 9 Plastic deformation of specimens A to D. a Specimen A. b Specimen B. c Specimen C. d Specimen D (Etching: Nital 3 \%)
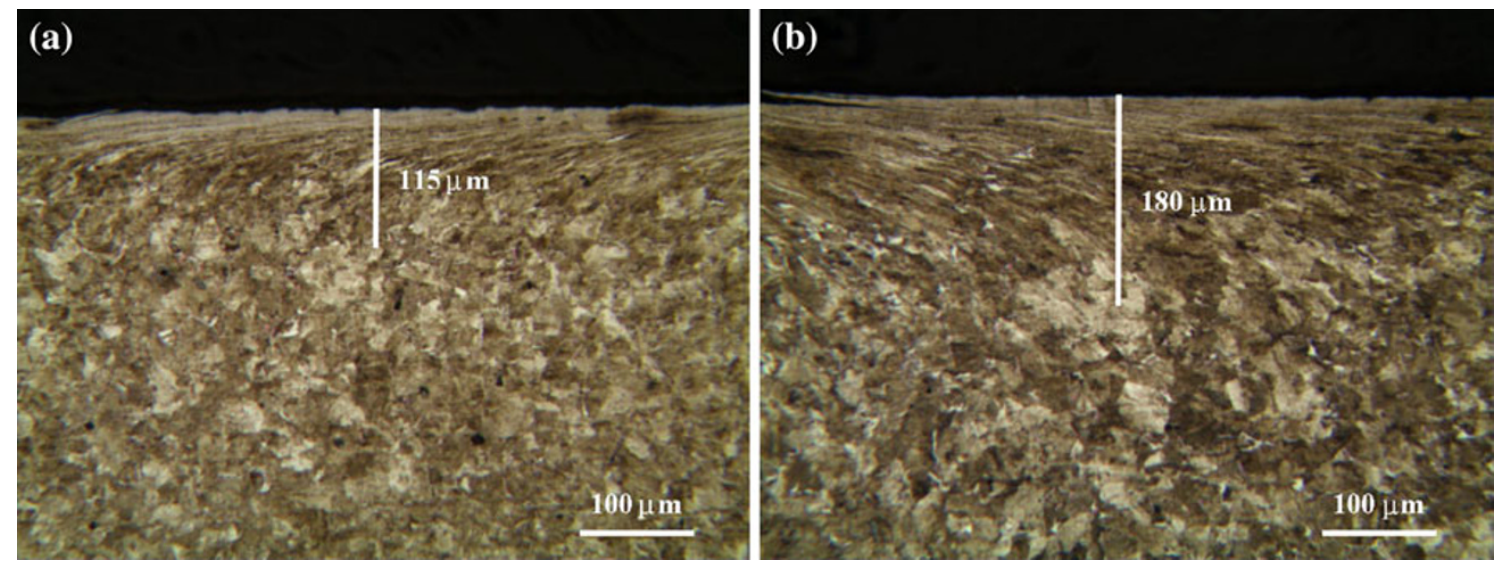

Fig. 10 Plastic deformation of specimens E and F. a Specimen E. b Specimen F (Etching: Nital $3 \%$ )

The hardness increments of lower carbon content materials is smaller, as shown in Fig. 8a, and hardness has a direct influence on wear resistance. There are fewer surface cracks on specimens $\mathrm{A}, \mathrm{B}$, and $\mathrm{C}$ compared with specimen $\mathrm{D}$ in Fig. 5, which means that specimen $\mathrm{D}$ exhibits more of the fatigue damage mechanism than do the other specimens. A smaller hardness increment makes less of a contribution toward improving the wear resistance, so the weight loss of lower carbon content materials is much greater than in the others. This indicates that for these specimens the wear mechanism is the dominant damage form, and the SEM observations of worn surfaces in Fig. 5 corroborate this.

Changing the test rotation speed can also lead to a change of the damage mechanism on the wheel surface. 

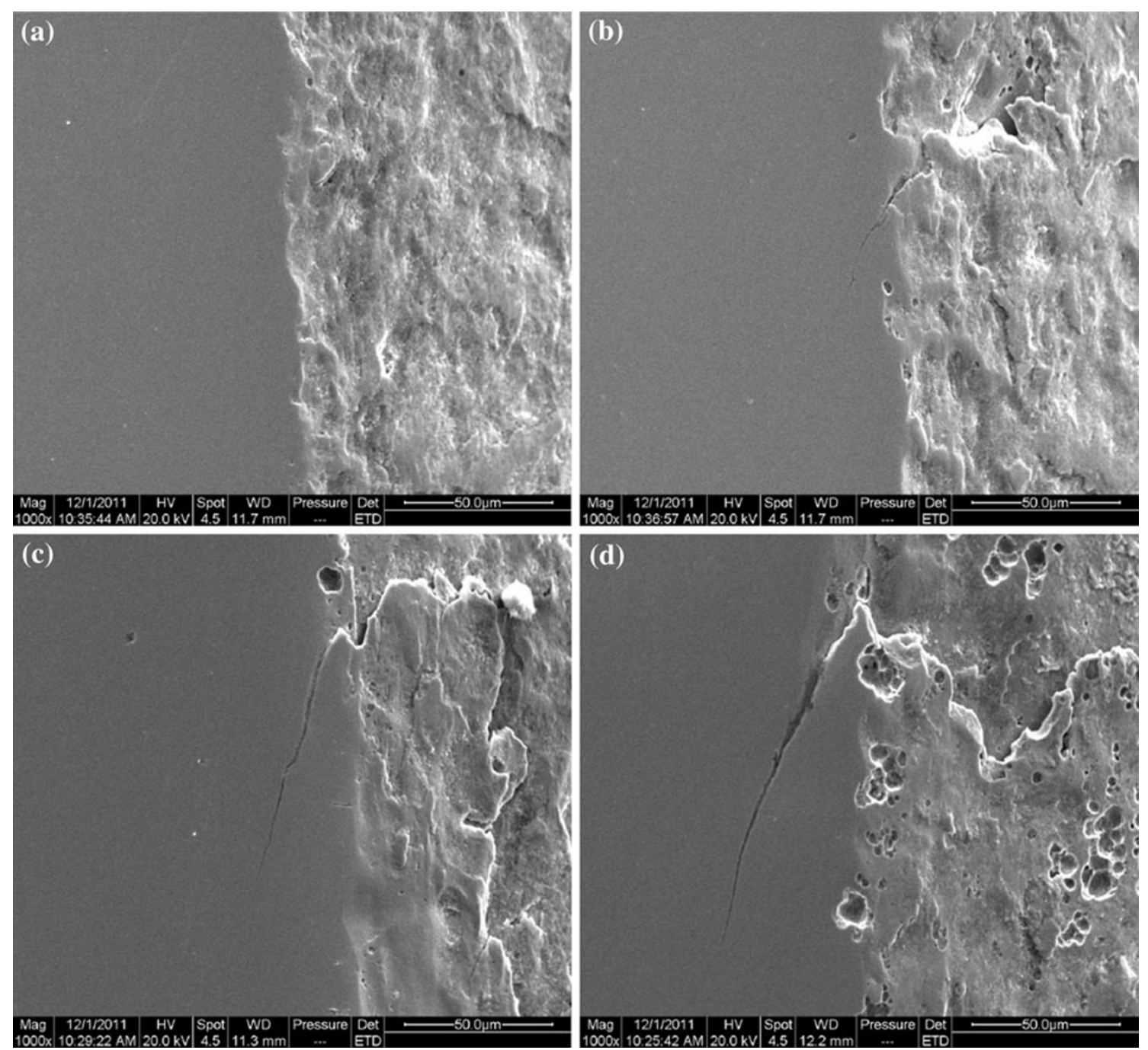

Fig. 11 The SEM of four specimens for different materials, the left side is cross section and the right side is contact surface. a A. b B. c C. d D

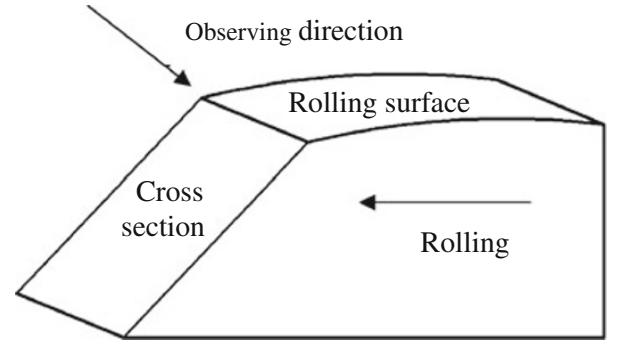

Fig. 12 Scheme of SEM observing

The specimen surfaces exhibit a wear-dominant mechanism when the test rotation speed is low and transition into a fatigue-dominant mechanism when the test rotation speed increases. Analyzing specimens E and F, we see that the cracks in specimen $\mathrm{E}$ are smaller and more numerous (Fig. 13a), and the weight loss of specimen $\mathrm{F}$ is much greater and the cracks are larger (Fig. 13b). This means that the wear mechanism is more dominant in specimen $\mathrm{E}$ than in F, and the cracks in specimen $\mathrm{E}$ were ground off before propagating. From the SEM observations of the plastic deformation (Fig. 10), we also find that the thickness of the plastic deformation layer in specimen $E$ is smaller than $\mathrm{F}$, which means that the fatigue damage mechanism is secondary and the wear mechanism is dominant.

Two effects influence the transition of the damage form mechanism upon changing the test rotation speed. On one hand, the increasing test rotation speed reduces the wear loss of the wheel roller so that the influence of the wear mechanism in specimen $\mathrm{F}$ is less. On the other hand, increasing the test rotation speed can increase the vibration of the simulated rollers, which can increase the dynamic load coefficient of the contact load between the simulated rollers. This effect can increase the fatigue damage and hardening of the contact surface, and the results in Figs. 8b, 

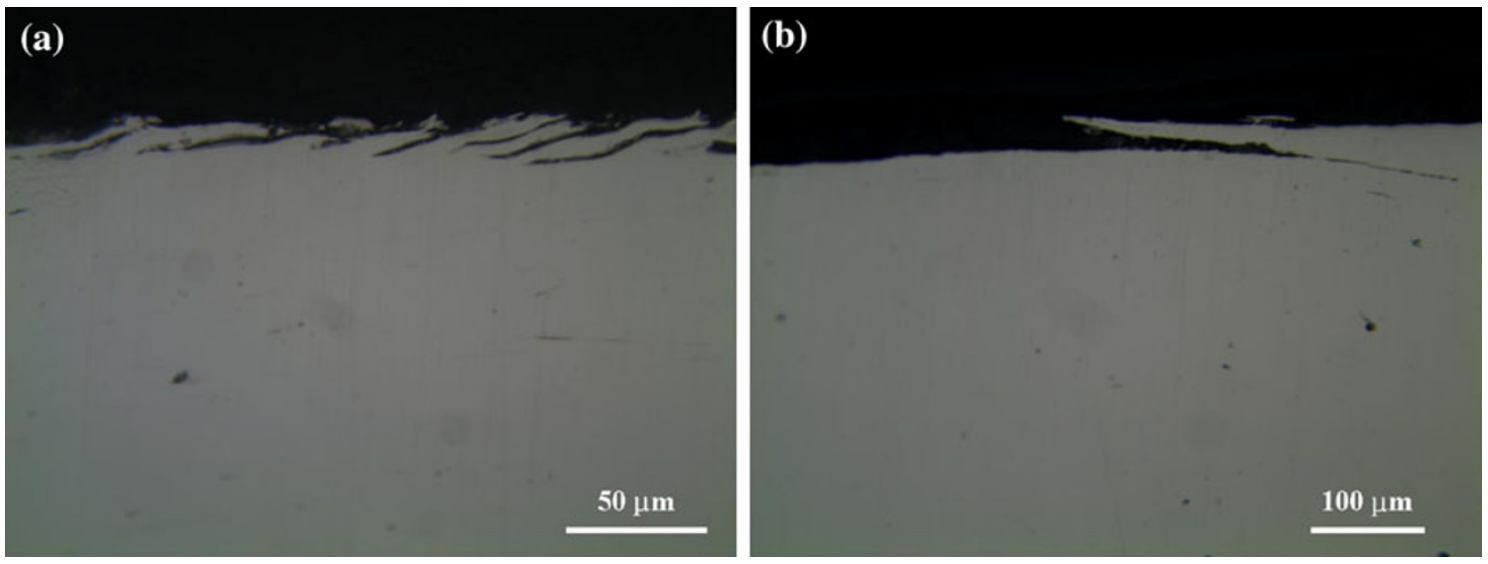

Fig. 13 Optical microscope image of three specimens on different rotational speed. a E. b F

10, and 13 all show evidence of this. Both of these effects transition the damage mechanism from wear-dominant into fatigue-dominant as the rotation speed increases.

According to the experimental results, under the same rolling conditions, the weight loss of a specimen reduces as the carbon content of the material increases. The surface hardness of all specimens is found to increase and the wear resistance thereby improves. The fatigue resistance of a material is also seen to be related to the carbon content.

Comparing the four materials, the wear resistance of the \#4 material is better than the others, but because the wear of the wheel and the rail must both be taken into account, the wear resistance is not the only aspect to consider when choosing a material [1]. Although the specimens using the \#1 material didn't exhibit any cracks in the surface cross section, these specimens experienced a much greater weight loss than specimens made from the other materials, making material \#1 a poor choice of steel for actual wheels for economic reasons. Therefore, both \#2 and \#3 materials are proper choices for railway operation because material \#2 has good fatigue resistance and material \#3 has good wear resistance. The \#2 material is suitable for high-speed railway operation and the \#3 material is suitable for heavy axle operation.

\section{Conclusions}

In this paper, the fatigue and wear characteristics of four types of wheel materials are investigated using chemical composition analysis, rolling contact fatigue, and wear bench tests on a JD-1 apparatus, profile analysis and micromorphology analysis. The conclusions from this study are as follows:

1. Both the wear resistance and the fatigue resistance are directly related to the carbon content of each material.
The wear resistance has a positive correlation with the carbon content, while the fatigue resistance has a negative one. After 106 rotations during rolling tests in the JD-1 wheel/rail simulation facility, uneven wear occurred on all of the specimens.

2. The relationship between flaking due to ratcheting and the adhesive wear mechanism can influence the topography of scars.

3. As the rotation speed of the rolling test increases, the hardness increments, and the thickness of layers exhibiting a steep hardness gradient are seen to increase.

4. All cracks initiate at and propagate along the plastic deformation line, and the extent of the severity of fatigue damage, such as length of the fatigue crack, has a positive correlation with the carbon content of the material.

The analysis suggests that both \#2 and \#3 materials are proper choices for railway operation, because their resistance to wear and fatigue is moderate and they have the capacity to achieve a state of steady wear.

Acknowledgments The work is supported by National Natural Science Foundation of China (Nos. 51174282, U1134202), the Fundamental Research Funds for the Central Universities (No. SWJTU12CX037), and Project supported by the Innovative Research Teams in Universities (No. IRT1178).

Open Access This article is distributed under the terms of the Creative Commons Attribution License which permits any use, distribution, and reproduction in any medium, provided the original author(s) and the source are credited.

\section{References}

1. Jin XS, Liu QY (2004) Tribology of wheel and rail. China Railway Press, Beijing

2. Robles Hernández FC, Kalay S, Stone D, Cummings S (2011) Properties and microstructure of high performance wheels. Wear 271:374-381 
3. Mi GF, Liu YL, Zhang B et al (2009) Wear property of cast steel wheel material in rail truck. J Iron Steel Res Int 16(3):73-77

4. Cvetkovski K, Ahlström J, Karlsson B (2011) Monotonic and cyclic deformation of a high silicon pearlitic wheel steel. Wear 271:382-387

5. Mazzù A, Donzella G, Faccoli M et al (2011) Progressive damage assessment in the near-surface layer of railway wheel-rail couple under cyclic contact. Wear 271:408-416

6. Olofsson U, Telliskivi T (2003) Wear, plastic deformation and friction of two rail steels - a full-scale test and a laboratory study. Wear 254:80-93

7. Liu QY, Zhang B, Zhou ZR (2003) An experimental study of rail corrugation. Wear 255:1121-1126

8. Garnham JE, Davis CL (2011) Very early stage rolling contact fatigue crack growth in pearlitic rail steels. Wear 271:100-112

9. Kapoor A, Franklin FJ, Wong SK, Ishida M (2002) Surface roughness and plastic flow in rail wheel contact. Wear 253:257-264

10. Chen H, Ban T, Ishida M, Nakahara T (2002) Adhesion between rail/wheel under water lubricated contact. Wear 253:75-81
11. Sakamoto H, Toyama K, Hirakawa K (2000) Fracture toughness of medium-high carbon steel for railroad wheel. Mater Sci Eng A 285:288-292

12. Ringsberg JW, Lindbäck T (2003) Rolling contact fatigue analysis of rails including numerical simulations of the rail manufacturing process and repeated wheel-rail contact loads. Int $\mathbf{J}$ Fatigue 25:547-558

13. Wang WJ, Shen P, Song JH et al (2011) Experimental study on adhesion behavior of wheel/rail under dry and water conditions. Wear 271:2699-2705

14. Zhong W, Hu JJ, Li ZB et al (2011) A study of rolling contact fatigue crack growth in $\mathrm{U} 75 \mathrm{~V}$ and $\mathrm{U} 71 \mathrm{Mn}$ rails. Wear 271:388-392

15. Zapata D, Jaramillo J, Toro A (2011) Rolling contact and adhesive wear of bainitic and pearlitic steels. Wear 271:393-399

16. Tyfour WR, Beynon JH, Kapoor A (1995) The steady state wear behaviour of pearlitic rail steel under dry rolling-sliding contact conditions. Wear 180:79-89

17. Beynon JH, Garnham JE, Sawley KJ (1996) Rolling contact fatigue of three pearlitic rail steels. Wear 192:94-111 